\title{
AÇÕES DESENVOLVIDAS PELO COORDENADOR PEDAGÓGICO EM TEMPO DE PANDEMIA: UM RELATO DE EXPERIÊNCIA
}

\author{
C. A. L. DE O. PÁDUA ${ }^{1}$, A. D. FRANÇA-CARVALHO ${ }^{2}$ \\ Universidade Federal do Piauí \\ ORCID ID: https://orcid.org/0000-0001-5291-2448 ${ }^{1}$ \\ calopadua1@hotmail.com ${ }^{1}$
}

Submetido 16/10/2020 - Aceito 16/10/2020

DOI: $10.15628 /$ holos.2020.11393

\section{RESUMO}

O coordenador pedagógico é um dos profissionais que contribui para a gestão na escola e para o sucesso do processo de ensino e aprendizagem dos alunos. Em tempos de pandemia ocasionada pelo COVID-19 este profissional, inexoravelmente, tem reinventado seus modos de agir para cumprir sua função. Nesse contexto, este artigo reflete acerca das ações empreendidas pelo coordenador pedagógico no ensino remoto. O relato transcorre da inquietação em dialogar acerca de suas atribuições, da participação na organização da escola, dos desafios encontrados no acompanhamento pedagógico, das novas ações no exercício profissional e do processo de formação de professores circunscritas pela pandemia. Nossa abordagem metodológica é qualitativa (BRASILEIRO, 2013), do tipo descritivo (GIL, 2008) e bibliográfico (GIL, 2010), com embasamento teórico sobre o relato de experiência fundamentado em Daltro e Faria (2019). Os diálogos e reflexões efetuadas evidenciaram o esforço do coordenador pedagógico para compreender e agir diante do processo de ensino e aprendizagem remoto. Também nos levou a inferir na dinamicidade de sua aprendizagem e interação de forma virtual com os pares e estudantes e na invenção de estratégias e ações formativas adequadas ao novo contexto de modo a contribuir com o desenvolvimento dos professores. Acreditamos que esse aporte reflexivo possa colaborar com outros profissionais da educação, além do coordenador pedagógico, na compreensão do movimento educativo e social. $E$, do mesmo modo, auxiliar na produção de saberes referentes à remoticidade do ensino.

PALAVRAS-CHAVE: Coordenador pedagógico, Ensino remoto, Pandemia.

\section{ACTIONS DEVELOPED BY THE PEDAGOGICAL COORDINATOR IN PANDEMIC TIME: AN EXPERIENCE REPORT}

\begin{abstract}
The pedagogical coordinator is one of the professionals who contributes to school management and to the success of the students' teaching and learning process. In times of pandemic caused by COVID-19, this professional has inexorably reinvented his ways of acting to fulfill his function. In this context, this article reflects on the actions taken by the pedagogical coordinator in remote education. The report stems from the concern to dialogue about their duties, participation in the organization of the school, the challenges encountered in the pedagogical monitoring, the new actions in professional practice and the process of teacher training circumscribed by the pandemic. Our methodological approach is qualitative (BRASILEIRO, 2013), descriptive (GIL, 2008) and bibliographic (GIL, 2010), with a
\end{abstract}

theoretical basis on the experience report based on Daltro and Faria (2019). The dialogues and reflections carried out showed the effort of the pedagogical coordinator to understand and act in the face of the remote teaching and learning process. It also led us to infer the dynamics of their learning and interaction in a virtual way with peers and students and in the invention of strategies and training actions appropriate to the new context in order to contribute to the development of teachers. We believe that this reflective contribution can collaborate with other education professionals, in addition to the pedagogical coordinator, in understanding the educational and social movement. And, likewise, assist in the production of knowledge regarding the remoteness of teaching.

KEYWORDS: Pedagogical coordinator, Remote education, Pandemic. 


\section{CONSIDERAÇÕES INICIAIS}

A instituição escolar de Educação Básica, pode ser constituída pela educação infantil, ensino fundamental e ensino médio, apresentando em todos estes níveis de ensino estrutura funcional que requer a participação de diferentes profissionais que contribuem para o desenvolvimento do processo educativo. Estes profissionais também respondem pelo processo de transformação de perspectivas dos estudantes, para que esses possam vivenciar o ato de aprender, atribuir valores a um futuro emprego, e consequentemente empreender uma autonomia. E dentre eles, situamos o coordenador pedagógico cujo papel é conduzir suas ações em direção ao sucesso do processo de ensino e aprendizagem, mesmo diante de situações adversas.

Nessa contextualização de adversidade, é que o governo público, as escolas e as famílias, buscam soluções em decorrência da pandemia causada por um vírus, que tem provocado o isolamento das pessoas, o distanciamento entre os cidadãos, o fechamento tanto do comércio e de órgãos governamentais, quanto de escolas em geral. Entende-se que todos os setores foram afetados, e que a instituição escolar foi também prejudicada em relação ao cumprimento das 800 horas de aulas e 200 dias letivos durante o período anual (BRASIL, 1996).

No entanto, em todo o mundo é notória a busca de novas formas de dar continuidade ao ano escolar de 2020, por meio de atividades não presenciais, ou remotas. No Brasil, especificamente no Piauí, podemos exemplificar o esforço das escolas em oferecer material de aprendizagem impresso e entregue aos familiares dos estudantes, e realização de conferências por aplicativos de vídeo e áudio na qual se reúnem a equipe gestora, docentes e discentes. Todos buscam continuar a ensinar e aprender, sendo imprescindível nesse momento, o uso de outras plataformas e recursos tecnológicos enquanto novo ambiente de sala de aula.

O espaço físico em que antes se reuniam professores, coordenador pedagógico, gestores e estudantes, deu lugar a outro espaço, o virtual onde interagem que por meio de outros mecanismos - tablet e celular, por um relevante período. Ressalte-se que esses instrumentos eram utilizados para outras finalidades, lúdica e comercial como conversas e compras hoje, na segunda década do século XXI torna-se comum fomentar ambientes virtuais para uso dos que estão envolvidos no processo educativo, como os profissionais e família.

Situado nessa conjuntura de "sobrevivência", o coordenador pedagógico, tem se redescoberto diante de situações antes não vivenciadas e tampouco discutidas na graduação em licenciatura. Diante desse contexto de incertezas e aprendizagem pelo acerto e erro, que propomos refletir as ações empreendidas por esse profissional em tempo de pandemia, a partir das experiências educativas desenvolvidas enquanto ações inerentes a função.

Tais atribuições são em prol de uma comunidade escolar, especificamente de uma instituição pública, localizada no município de Teresina-Piauí, e que se encontra fechada, atendendo a solicitação dos órgãos responsáveis. Diante dessa prerrogativa, e embasados em autores que descrevem o coordenador pedagógico, elencamos ideias e perspectivas realizadas para minimizar os prejuízos ocasionados pela pandemia, desenvolvendo assim, a urgência de um modelo de 
trabalho para ser realizado por meio de algumas plataformas que eram desconhecidas em sua amplitude de usabilidade. Portanto, a partir dessas considerações, é relevante conhecermos o trajeto metodológico que nos permitiu o encadeamento necessário para o processo do estudo e de análise.

\section{METODOLOGIA}

Para o desenvolvimento do relato de experiência, foi necessária uma sistematização metodológica, que contemplasse o conhecimento científico. A partir desse propósito, entendemos que a ciência, também afirma que a produção de ideias deve ser em prol da sociedade. Nesse sentido, entendemos que o nosso trabalho apresenta uma abordagem qualitativa, que segundo Brasileiro (2013), a mesma concebe as situações, sem a utilização de mecanismo estatístico. Por meio dessa contribuição, foi possível apresentar os pensamentos, mediante as nossas experiências.

Nesse aspecto, utilizamos a proposta de relatar diversas atividades cotidianas, por meio da sugestão de Gil (2008, p. 28), que caracteriza de forma esclarecedora a pesquisa descritiva, ou seja,

As pesquisas deste tipo têm como objetivo primordial a descrição das características de determinada população ou fenômeno ou o estabelecimento de relação entre variáveis. [...]. São incluídas neste grupo de pesquisas que têm por objetivo levantar as opiniões, atitudes e crenças de uma população.

Aliada a essa condição de explicação, usufruímos também da pesquisa bibliográfica, que de acordo com o mesmo autor trata da produção do estudo, utilizando o embasamento por meio de fontes, como artigos e a web. Nesta perspectiva a pesquisa descritiva é considerada como o alicerce em relação a teoria do estudo, e o esclarecimento do que já foi analisado em relação a uma vertente do conhecimento.

Por fim, utilizamos o relato de experiência, enquanto apresentação das ações desenvolvidas pelo coordenador pedagógico durante o período de pandemia, recorrendo ao seguinte entendimento, isto é,

[...] Relato de Experiência como uma importante narrativa científica afinada à condição pósmoderna. Trata-se de uma narrativa que, através da linguagem, performatiza a experiência de singularização, atestada em um dinamismo descentrado da razão, e apta a suportar paradoxos. O RE está compreendido como um trabalho de linguagem, uma construção que não objetiva propor a última palavra, mas que tem caráter de síntese provisória, aberta à análise e à permanente produção de saberes novos e transversais. Configura-se como narrativa que, simultaneamente, circunscreve experiência, lugar de fala e seu tempo histórico, tudo isso articulado a um robusto arcabouço teórico, legitimador da experiência enquanto fenômeno científico (Daltro; Faria, 2019, p. 235).

Diante dessas considerações, propomos refletir nossa prática, e auxiliar outros coordenadores pedagógicos no desenvolvimento de sua função no trabalho home office, na assertiva de colaborar com a educação, de modo geral. 


\section{REFLEXÕES ACERCA DAS ATRIBUIÇÕES DO COORDENADOR PEDAGÓGICO}

Para refletir sobre as atividades a serem desenvolvidas pelo coordenador pedagógico, é necessário relacionar as suas ações com o processo de ensino e aprendizagem, organizando nesse sentido, desde a entrada do estudante na escola, até mesmo o seu desempenho enquanto pessoa na sociedade. Essas concepções estão imbricadas com outras vertentes, que ora se complementam, ora são os princípios para o sucesso escolar. Nesse sentido, tentaremos dialogar a seguir sobre o coordenador pedagógico e sua participação na gestão escolar, desafios no acompanhamento pedagógico, novas ações no exercício profissional, e o processo de formação de professores.

\subsection{O COORDENADOR PEDAGÓGICO E SUA PARTICIPAÇÃO NA GESTÃO ESCOLAR}

A gestão escolar compreende um conjunto sistematizado de ideia, reflexão e organização referente a prática educativa, que é desenvolvida em uma instituição, a partir de profissionais, que em equipe lideram pessoas e / ou grupos de pessoas durante a escolha de determinadas situações. Faz parte dessas iniciativas, o bom senso, para intermediar conflitos e conduzir os participantes do contexto, a uma proposta ética e acordada entre todos.

Essa proposta, dialoga com uma prática respeitadora, em um lócus emergido de atenção e altruísmo, com foco na transformação e autonomia, mediante as diferentes condições dos cidadãos. A partir desse viés, consideramos relevante que as concepções educativas sejam alinhadas entre todos os interessados em ouvir e propor alternativas e/ou estratégias, para o bem-estar da comunidade.

Referente a essa demanda social que necessita de uma resolutividade, emerge o trabalho do coordenador pedagógico, que pode contribuir de acordo com suas condições, no desenvolvimento de reuniões, bem como, propor sugestões. Esse por sua vez, tem suas atribuições intimamente relacionadas ao trabalho exercido pelo diretor da escola, vice diretor ou diretor adjunto e secretário da instituição, na perspectiva de dinamizar as tarefas, e promover ações que mobilizem atitudes assertivas no espaço interno e externo ao prédio. Dentre tantas responsabilidades, ainda lhe cabe o papel de formador dos professores da escola. De fato,

No Brasil, a figura do coordenador pedagógico é relativamente conhecida. Embora haja um consenso geral sobre suas atribuições, o estatuto da coordenação pedagógica ainda é disperso, falta uma unidade que sintetize os aspectos conceituais, estruturais e políticos da ação desse profissional nas escolas espalhadas pelo território brasileiro e que institua uma profissionalidade de coordenador pedagógico (Domingues, 2014, p. 14-15).

Esse pensamento relevante nos ajuda a refletir o quanto a profissão precisa de atenção e de sistematização dos fazeres profissional, para que esse possa articular juntamente com os demais componente da gestão, diferentes maneiras de não subjugar o desenvolvimento do seu trabalho, que é desempenhado por meio de responsabilidades.

Durante o nosso dia a dia, em tempo de pandemia, procuramos estar disponível para as necessidades da escola. Enquanto gestor escolar, participamos de diversas reuniões virtuais, ou seja, com a diretora e representante da secretaria de educação para dialogarmos sobre as atividades 
não presencial do coordenador pedagógico; com o conselho escolar, para as decisões necessárias a serem empreendidas pela escola; de reuniões formativas com a diretora e professores; com os estudantes, para engajá-los no processo de ensino e aprendizagem, e outras situações a serem descritas no decorrer do estudo.

Entendemos que nesse momento delicado, em que as preocupações com a saúde são latentes, não medimos esforços para atender as necessidades da comunidade escolar, nos mais diversos turnos e dias da semana. Percebemos que mesmo sendo cansativo, estamos desenvolvendo ações que legitimam a nossa profissão, em razão do compromisso com o serviço público. A diferença do espaço de trabalho, oportunizou a criação de novos conhecimentos a serem aprendidos e colocados em prática, mesmo diante de inúmeros desafios.

\subsection{DESAFIOS NO ACOMPANHAMENTO PEDAGÓGICO}

Em tempo de pandemia, somos desafiados enquanto coordenador pedagógico, a manter ou melhorar a qualidade da comunicação com aqueles que compõem a comunidade escolar. Os diálogos presenciais foram substituídos por videoconferências, requerendo nesse momento atenção redobrada no que seria apresentado, tanto na fala, quanto nas imagens. Houve também, o aumento de solicitações dos pais e / ou responsáveis, bem como dos professores, por meio do WhatsApp, onde todos são prontamente atendidos, bem como apresentada uma devolutiva. $\mathrm{E}$ buscamos ainda desenvolvermos uma linguagem clara por meio de técnicas de oratória, para que assim, a interação aconteça de forma dinâmica.

Outra situação, foi desenvolver o processo de formação juntamente com os professores, seja no planejamento semestral e bimestral, seja durante o horário pedagógico. Anteriormente, nos reuníamos presencialmente, e elencávamos as propostas para encontrarmos um consenso. Com o distanciamento social, passamos a realizar os momentos formativos virtualmente, sendo observado que a participação dos professores era tímida, mesmo esclarecendo que o pensamento de todos é relevante. Nesse sentido, percebemos que a participação docente aumentou, quando as formações são dialogadas no horário pedagógico, devido ser individual, ou seja, entre professor, coordenador pedagógico e diretora.

Referente a autoformação, tivemos que aprender com urgência, sobre a utilização de ferramenta e aplicativo digitais, que pudessem ser práticos e que contribuíssem nas nossas atividades. Para tanto, analisamos: o custo e benefício, a facilidade de utilização, se apresentava adequação para o celular e computador, se haveria uma aceitação por parte da equipe, e se o retorno dos dados seria otimizado. Essa experiência decorreu por um tempo, até recebermos o feedback dos profissionais - professores e diretora, sinalizando que havia interesse em utilizar os que tinham sido indicados. Avaliamos essa decisão como um processo democrático, sendo possível a liberdade para o uso das tecnologias ofertadas.

Ao se pensar nas tecnologias, foi prevista a ideia de aliar tempo e produtividade no fazer pedagógico. Logo no início das aulas não presenciais, ocorre o aligeiramento de tentar "se adequar" a nova realidade, que exige da gestão escolar respostas para várias indagações, dentre essas: 0 que fazer para desenvolver o nosso trabalho com qualidade? Qual material pedagógico deve ser 
produzido para o processo de ensino e aprendizagem? Como avaliar os estudantes? O que fazer para aumentar a participação / frequência dos estudantes na aula virtual? Como desenvolver "todas" as ações diante do tempo? Essas perguntas é uma parcela de questionamentos que ilustra o início desse momento, que tem nos desafiado a pensar e produzir com urgência.

Nesse contexto, observamos o pensamento de Costa (2019), ao descrever que a atividade desse profissional em buscar novas ideias e refletir sobre o seu fazer, objetiva um sucesso tanto no ato de ensinar, quanto no aprender.

Compreendemos ainda, que diante de uma demanda que exige atenção e pouco tempo para a realização, é imprescindível que a equipe gestora e equipe docente, estejam dispostos a contribuir, de acordo e respeitando as próprias limitações físicas, e sempre que possível, recorrendo aos órgãos públicos, para os devidos direcionamentos. Diante do exposto, é possível entender o contexto desafiador da pandemia para o processo de atividade do coordenador pedagógico, a partir da Figura 1, que segue:
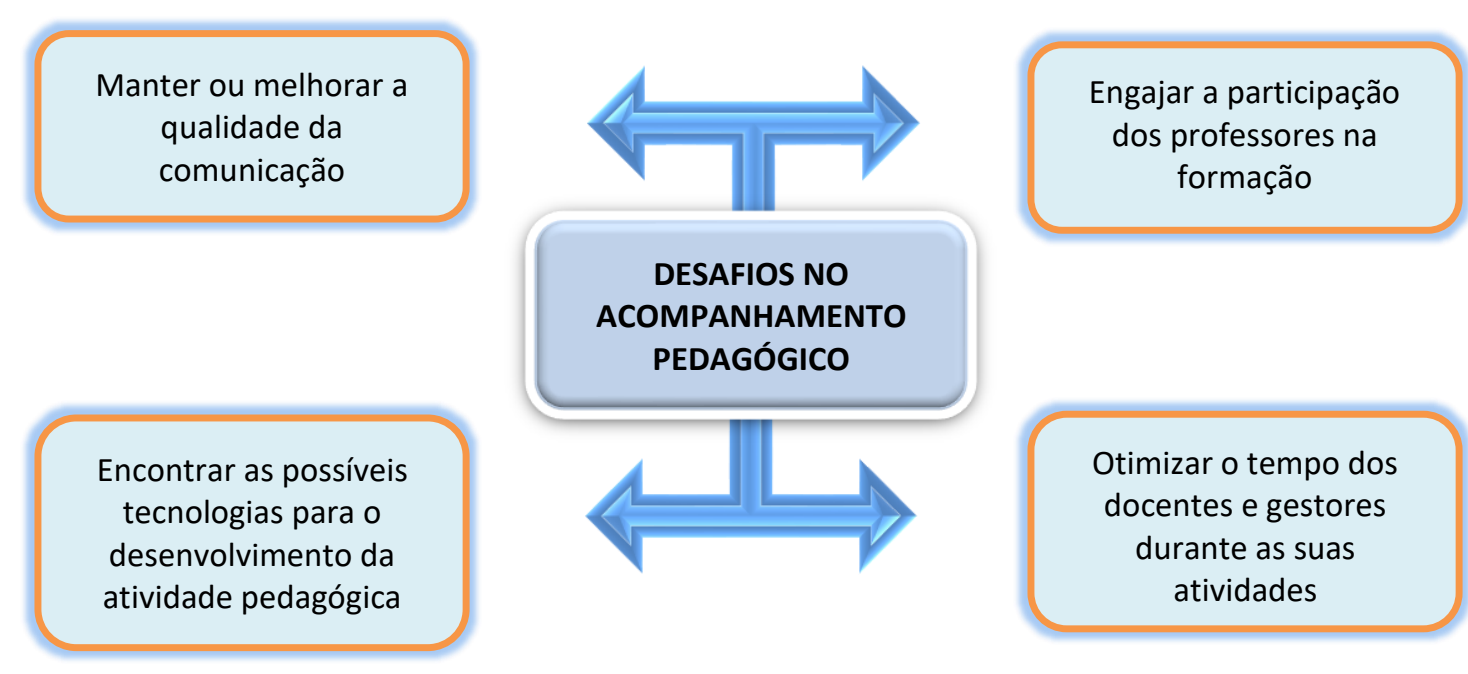

Figura 1: Desafios encontrados pelo coordenador pedagógico.

Fonte: Dados dos autores, 2020.

E para tentar encontrar possíveis respostas de como continuar a realizar as atribuições inerentes a profissão, foram desenvolvidas algumas novas ações pertinentes, que só foram possíveis de realizá-las, pela participação em conjunto.

\subsection{NOVAS AÇÕES NO EXERCÍCIO PROFISSIONAL}

Em decorrência da pandemia, ocorreu a decisão governamental pelo distanciamento social e consequentemente interrupção das aulas na escola. Posteriormente foram realizadas reuniões pelos profissionais da secretaria de educação, para a apresentação aos gestores, sobre o novo formato de encontros pedagógicos entre professor e estudantes. Em seguida, nos reunimos para repensar como iríamos desenvolver o processo de ensino e aprendizagem no contexto não presencial. 
Nesses momentos, refletimos em relação a atividade da diretora, professores, família e coordenador pedagógico. A partir do diálogo, nos pusemos durante alguns dias, a estruturar o planejamento escolar, sistematizar o acompanhamento dos professores e estudantes, dentre outras dinâmicas que compete a nossa profissão. Mesmo diante dos desafios a serem superados, vislumbramos a opção de servir. Para tanto, buscamos "aprender" o que possivelmente seria o melhor para ser trabalhado com os componentes da comunidade escolar.

Nesse sentido, fomos compreender como seria ou como aconteceria a dinâmica do processo, e em seguida, organizamos o planejamento. Para Farias et al (2014, p. 107), "a prática educativa, como intencional e sistemática, precisa ser organizada previamente, o que se concretiza por meio do planejamento das ações didáticas e pedagógicas da escola".

A partir desse entendimento, pensamos em aliar diferentes tecnologias com as particularidades da nossa prática, mas havia a necessidade de saber como utilizá-las. Durante esse período, aprendemos ora sozinho, ora com ajuda de integrante da família, o processo de manuseio de variadas tecnologias. Depois que conhecemos o básico sobre determinados programas, foi possível ensinar os professores. Essa ajuda para contribuir na desenvoltura desses, dentre outras ideias, melhorou a proximidade entre a equipe, pois houve novos compartilhamentos de pensamentos relacionado as preocupações dos docentes, de como fazer, o que abordar, o tempo do vídeo, a devolutiva para a família, e outras incógnitas.

O planejamento também nos ajudou a adequarmos os objetos de conhecimentos perante a realidade, pois havia a necessidade de contribuir com as orientações sobre a produção da atividade, bem como a formatação da imagem a ser enviada. O processo da escuta foi relevante nesse momento, pois no início, alguns professores não sabiam como agir diante de determinadas situações, nos levando a repensar novas sugestões de encaminhamentos para a aula, e para o dia a dia.

Com o uso frequente do celular e computador, no desenvolvimento das ações escolar, foi observado que as informações chegam com agilidade, e que elas precisam ser replicadas entre os professores de forma dinâmica. Nesse sentido, foi criado na internet um ambiente que contribuísse na praticidade e objetividade de organização dos materiais a serem utilizados, tanto pela secretaria de educação, quanto pelos gestores e professores.

A estratégia foi pensada, devido o cansaço gerado pela rotina. Durante o percurso, fomos fazendo as adequações necessárias, e verificamos a satisfação dos participantes no uso da ferramenta disponibilizada, alcançando o objetivo proposto. É também por meio dessas experiências exitosas, que percebemos a importância do desenvolvimento cíclico, ou seja, do profissional, da escola e da família.

Tais concepções elencadas, nos indicam que mesmo diante de momentos exaustivos, em que permanecemos conectados por um longo prazo a uma prática profissional, consideramos que o coordenador pedagógico cria, produz e considera estratégias para atividades humanizadas, pensada na saúde e performance dos profissionais. Assim como foram pensadas as novas ideias, na qual estão representadas na Figura 2, entendemos que as mesmas possam ser reestruturadas, para a obtenção de diferentes resultados em tempo de pandemia e após a essa situação. 


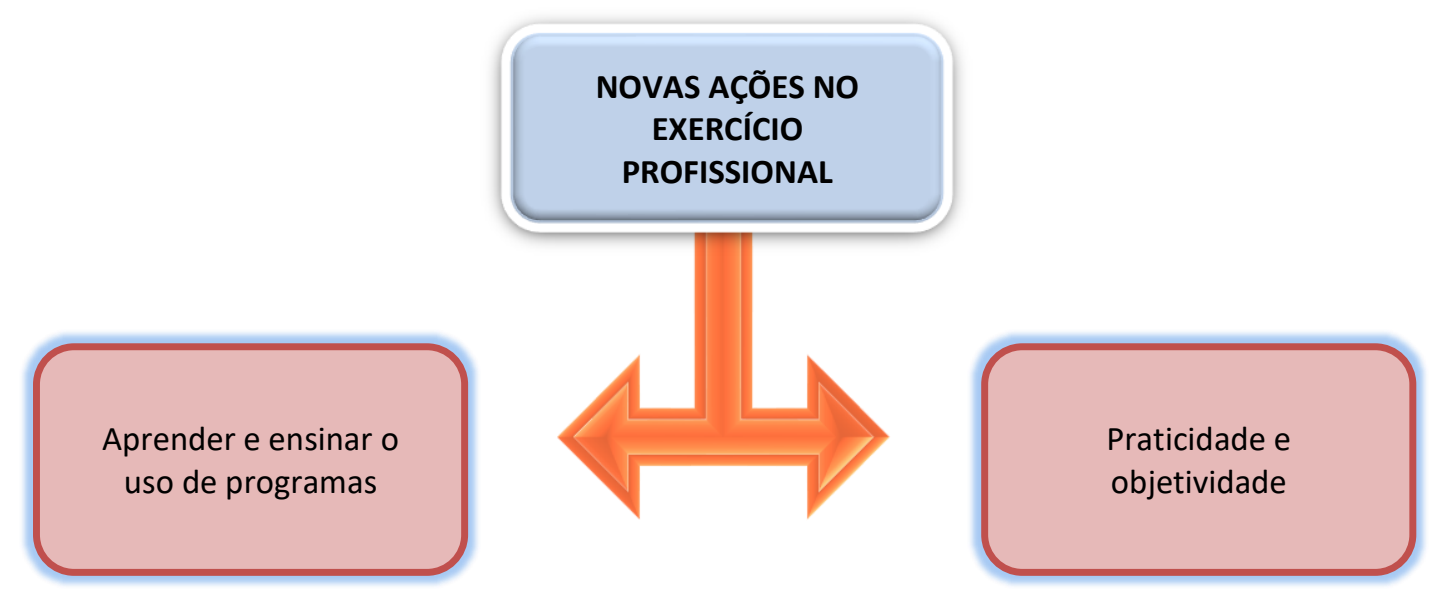

Figura 2: Novas ações desenvolvidas pelo coordenador pedagógico

Fonte: Dados dos autores, 2020.

Mediante a essas novas percepções, houve um processo formativo de professores, para que as propostas e decisões fossem acordadas entre a equipe, nos aproximando de uma prática democrática.

\subsection{O PROCESSO DE FORMAÇÃO DE PROFESSORES}

Nas redes públicas de ensino rotineiramente o coordenador pedagógico participa de formações virtuais para que aprender o desenvolvimento dos planos, programas e projetos, a serem realizados com os participantes da escola e multiplicar para os professores na escola. Enquanto coordenador pedagógico idealizamos que as formações de professores não se resumam aos informes burocráticos (que são necessários). Mas, também, que apresentem contribuições por meio de embasamentos científicos e questionamentos, para que a nossa participação social durante o processo de ensino e aprendizagem, seja em prol da transformação da realidade, mesmo diante da distância.

Nesse sentido, quando as formação ofertadas pela rede de ensino finaliza, estruturamos as formações para os professores, considerando o que seria realizado, como poderia ser desenvolvido, e quanto tempo seria necessário. A partir desses encaminhamentos, dialogamos com esses profissionais, e na oportunidade, utilizamos textos acadêmicos, citações teóricas, tentamos esclarecer as dúvidas, e entre outros. Na atual situação, em que os professores também estão em alerta, procuramos apresentar mensagens acolhedoras, de cunho altruísta, e informar que estamos disponíveis para ajudá-los.

Nossa intenção ao desenvolver estes processos formativos é a mesma de Imbernón, 2016, p. 179 ) ou seja, proporcionar ao professor no processo formativo " [...] elementos para alcançar uma maior independência de opinião, deliberação e diálogo construtivo; precisa ser capaz de ajudar a transformar as relações entre o professorado com as novas sensibilidades que vêm impregnando a sociedade atual". 
Ainda percebemos, que diante das inquietações promovidas pelas formações, os professores continuam a busca pela participação em cursos. Isso demonstra, que mesmo diante das limitações provocadas pela pandemia, os professores estão motivados a compreender o novo. "Sabemos que muitos aspectos sobre a formação docente se constroem no cotidiano, a partir do enfrentamento da sala de aula, na forma como os problemas são resolvidos, pois estes não aparecem em nenhum manual" (Rankel, 2009, p. 57).

A propósito, continuamos no processo de aprendizagem por meio participando das atividades do NIPEEPP (Núcleo Interdisciplinar de Pesquisa em Educação e Epistemologia da Prática Profissional) vinculado ao Programa de Pós-Graduação em Educação, da Universidade Federal do Piauí. Esses momentos têm propiciado conhecimentos inerentes ao exercício do coordenador pedagógico, que posteriormente são apresentados para a equipe de professores.

A partir desse contexto, ressaltamos a relevância da formação dos professores, enquanto processo de avaliar a prática pedagógica, acompanhar a participação dos estudantes, conhecer a prática docente, como asseveram Coutinho, Morais e França-carvalho (2020) e realçar as estratégias desenvolvidas diante das variadas situações encontradas, para então ser possível subsidiar o processo de ensino e aprendizagem por meio de suporte tecnológico e outros.

Nesse sentido, seguimos readaptando a nossa atividade, para que os encontros formativos, apresentem uma desenvoltura dinâmica, e que todos os envolvidos continuem sendo coparticipantes dos resultados alcançados, assim como as ações permaneçam sendo elaboradas continuamente, a partir das necessidades dos estudantes, professores, equipe gestora e sociedade.

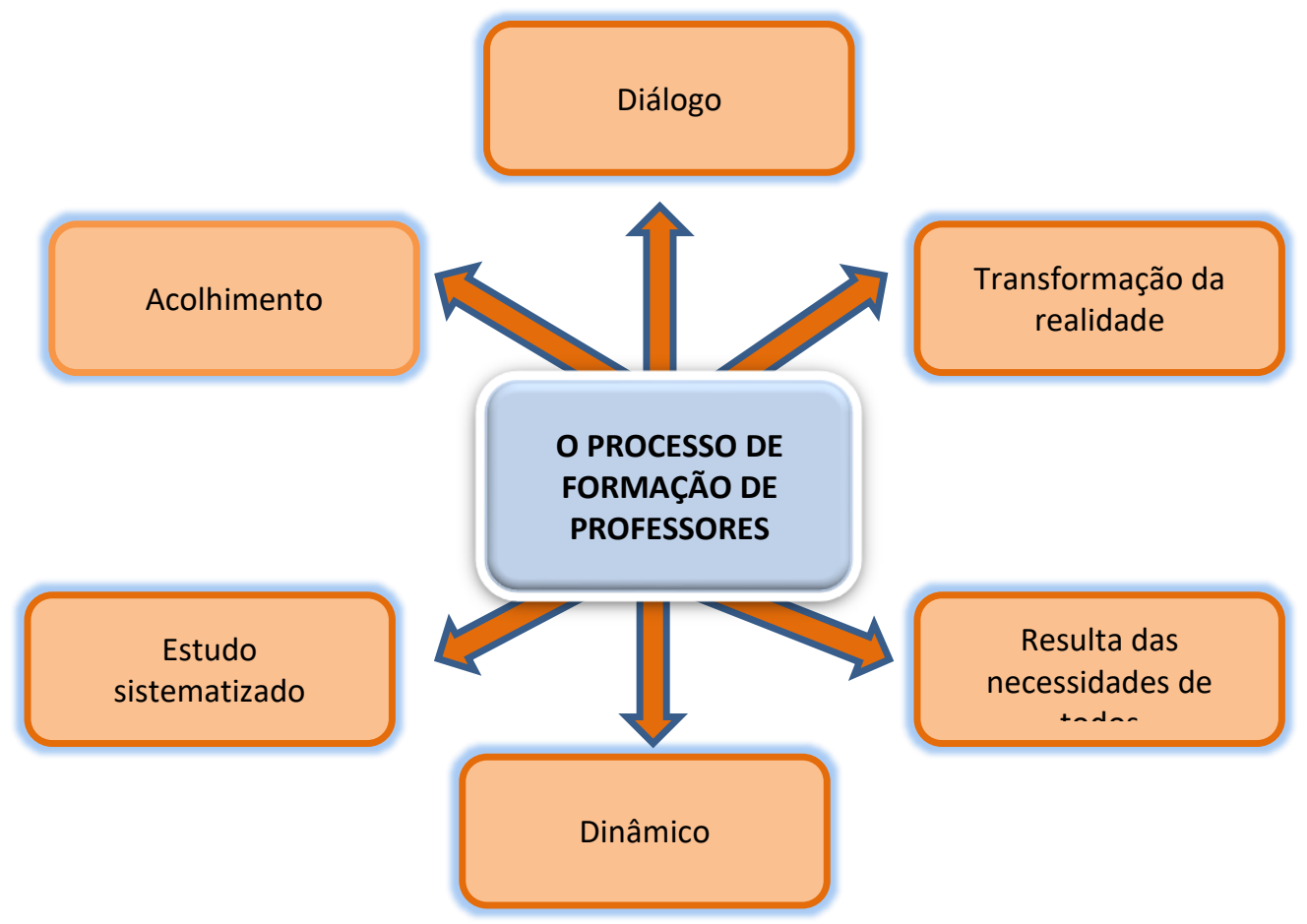

Figura 3: O processo de formação de professores desenvolvido pelo coordenador pedagógico

Fonte: Dados dos autores, 2020. 
Assim, diante das experiências apresentadas, e sintetizadas logo abaixo na Figura 3, analisamos que nossas atividades de coordenador pedagógico em tempo de pandemia, ajudam na construção de políticas sociais, em que o processo educativo ético, plural e com qualidade, é indispensável.

\section{CONSIDERAÇÕES FINAIS}

As atividades que temos desenvolvidos enquanto coordenador pedagógico, decorrem de estudos, experiências e formações. No entanto, fomos surpreendidos por uma pandemia que tem desafiado o processo de ensino e aprendizagem, ocasionando um trabalho exaustivo, em que exige uma constante resiliência.

Efetivamente, as responsabilidades ou outras ações, passaram a serem comunicadas por mensagens, e os diálogos começaram a ser constituídos de forma não presencial. E, nessas circunstâncias certezas deram lugar as dúvidas. Estávamos no caminho correto? A quem recorríamos, também não sabia a resposta. E elas foram sendo construídas.

Os estudos da literatura, puderam garantir um conforto daquilo que possivelmente poderia ser desenvolvido. E acertamos quando buscamos as tecnologias que eram direcionadas ao encontro dos nossos anseios. Mas era necessária a validação da nossa sugestão pelo demais envolvidos no contexto.

Notadamente, devido as incertezas da vacina, a experiência do ensino remoto permanece e isso significa que continuaremos a buscar novas estratégias e assim estaremos inovando nosso modus operandi de trabalhar na pandemia. Percebemos que essa ideia de criar, tem sido oportunizado pelo trabalho em conjunto, dia após dia, em que não são medidos os esforços, prevalecendo os cuidados com a saúde de todos. E que, diante das atividades não presenciais, o coordenador pedagógico pode desenvolver novas ações enérgicas com amor e responsabilidade, acreditando que ao sistematizar formações dos professores, o retorno em forma de aprendizagem é qualitativo.

Para finalizar lembramos que os riscos do momento, projetam olhares futuros sobre o processo de ensino e aprendizagem de uma forma não clássica ou tradicional. Porém, traz, também, a certeza de que o ensino remoto ou presencial implica na existência de pessoas que, embora não possam se abraçar mantêm um convívio rotineiro de estudos, de pesquisa, trazendo a esperança de um mundo melhor.

Esperamos com estas reflexões, apresentar à comunidade acadêmica e à sociedade, as vivências de um profissional que desenvolve múltiplas funções na escola para o sucesso do processo de ensino e aprendizagem, o coordenador pedagógico. Este profissional que, no exercício e sua função no cotidiano da remoticidade do ensino supera as adversidades e inova suas ações profissionais em defesa de uma práxis educativa.

Acreditamos que diante de sorrisos e lágrimas, possamos esperar também na pesquisa, respostas para os nossos questionamentos para composição de um conjunto de conhecimentos 
sobre esta forma real de ensinar e aprender imposta para o mundo no final da segunda década do século XXI.

\section{REFERÊNCIAS}

Brasil. (1996). Ministério da Educação. Lei no 9.394, de 20 de dezembro de 1996. Estabelece as diretrizes e bases da educação nacional. Brasília. Disponível em: <http://www.planalto.gov.br/ccivil_03/leis/19394.htm>. Acesso em: 28 ago. 2020.

Brasileiro, A. M. M. (2013). Manual de Produção de Textos Acadêmicos e Científicos. São Paulo: Atlas.

COUTINHO, H. R. N.; MORAIS, A. P. S.; França-Carvalho, Antonia Dalva; ARAUJO, Z. T. S.

Formação de professores: saberes e significados da ação docente. Revista Brazilian Journal of Development. , v.6, p.27422 - 27434, 2020.

Costa, A. F. M. Da et al.. (2019). "O coordenador pedagógico na escola de tempo integral: provocações para uma educação integral". Anais VI CONEDU... Campina Grande: Realize Editora. Disponível em: <https://www.editorarealize.com.br/index.php/artigo/visualizar/61274>. Acesso em: 05/09/2020 23:43

Daltro, M. R.; Faria, A. A. de. (2019). Relato de experiência: Uma narrativa científica na pósmodernidade. Estud. pesqui. psicol., Rio de Janeiro, v. 19, n. 1, p. 223-237, jan. Disponível em $<$ http://pepsic.bvsalud.org/scielo.php?script=sci_arttext\&pid=S1808$42812019000100013 \&$ Ing=pt\&nrm=iso>. acessos em 05 set. 2020.

Oliveira, I. X.; França-carvalho, A.D; Tavares, A. M. B. N. (2020). Política de responsabilização escolar (accountability school) e formação de professor: cenários e atores na avaliação educacional brasileira'. Revista Ibero-americana de estudos em educação. v.15, p.2049 - 2065, 2020.

Domingues, I. (2014). O Coordenador pedagógico e a formação contínua do docente na escola. 1. ed. São Paulo: Cortez.

Farias, I. M. S. de.; Sales, J. de O. C. B.; Braga, M. M. S. de C., \& França, M. do S. L. M. (2014). Didática e docência: aprendendo a profissão. 4. ed. Brasília: Líber Livro.

Gil, A. C. (2010). Como elaborar projetos de pesquisa. 5. ed. São Paulo: Atlas.

Gil, A. C. (2008). Métodos e técnicas de pesquisa social. 6. ed. São Paulo: Atlas.

Imbernón, F. (2016). Qualidade do ensino e formação do professorado: uma mudança necessária. [tradução Silvana Cobucci Leite]. São Paulo: Cortez.

Rankel, L. F. (2009). Profissão docente, ciência interdisciplinar e representações sociais. In: RANKEL, Luiz Fernando; STAHLSCHMIDT, Rosângela Maria. Profissão docente. Curitiba: IESDE Brasil S.A., p.57-69. 


\section{COMO CITAR ESTE ARTIGO:}

Pádua, C. A. L. de O., França-Carvalho, A. D. (2020). Ações desenvolvidas pelo coordenador pedagógico em tempo de pandemia: um relato de experiência. Holos. 36(6), 1-12.

\section{SOBRE OS AUTORES}

\section{A. L. DE O. PÁDUA}

Graduado em Pedagogia (UESPI). Mestre em Educação (UFPI). Doutorando em Educação (UFPI). Coordenador Pedagógico efetivo da Secretaria Municipal de Educação de Teresina - SEMEC-PI. E-mail: calopadua1@hotmail.com

ORCID ID: https://orcid.org/0000-0001-5291-2448

\section{A. D. FRANÇA-CARVALHO}

Doutora em Educação. Professora do Programa de Pós-Graduação em Educação (PPGEd) e do Departamento de Fundamentos da Educação (DEFE), da Universidade Federal do Piauí (UFPI). E-mail: adalvac@ uol.com.br. ORCID ID: https://orcid.org/0000-0002-9827-061X

Editor(a) Responsável: Francinaide de Lima Silva Nascimento

Pareceristas Ad Hoc: ANDREZZA TAVARES E FÁBIO SANTOS

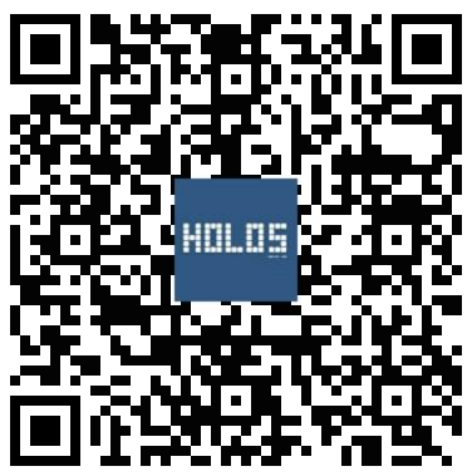

